\title{
Un aporte al "status quaestionis" sobre los estudios e investigaciones sobre el Jesús histórico
}

\section{A contribution to "status quaestionis" towards researching on the historical Jesus}

\section{Resumen}

El presente artículo hace una recensión de las más actuales líneas de investigación histórica y teológica en torno al Jesús histórico y sus implicaciones en la cultura y en la vida de la comunidad cristiana, reconociendo los avances y los límites de estas aproximaciones y la pertinencia de los esfuerzos hermenéuticos de contexto.

Palabras clave: Cristología; tercera búsqueda; hermenéutica; tercer mundo; feminismo.
Eduardo de la Serna ${ }^{1}$

DOI:10.29151/hojasyhablas.n20a2

${ }^{1}$ Doctor en Teología, Universidad del Teresianum (Roma) y Profesor en Sagradas Escrituras. Email: edelaserna96@gmail.com. ORCID: orcid.org/0000-00026459-5678

This article makes a review of the most current lines of historical and theological research on the historical Jesus and his implications in the culture and life of the Christian community, perceiving the advances and limits of these approaches and the relevance of the context hermeneutical work.

Keywords: Christology; Third Quest; Hermeneutics; Third World; Feminism. 


\section{Introducción}

Los trabajos sobre lo que convencionalmente llamaremos "Jesús histórico" son realmente abundantes, $y$ han pasado por una notable variación que se podría esquematizar como la tensión entre el escepticismo y la euforia, la imagen de que estamos ante un tema principal o un tema sin importancia alguna para la teología, o un tema que aporta mucho o casi nada para la pastoral o la vida cristiana. Sin embargo, el tema es recurrente una y otra vez. Por ejemplo, con frecuencia se suele decir, ante los reclamos feministas, que "la Iglesia no puede hacer algo distinto a lo que hizo Jesús". Dejo de lado toda hermenéutica y todo análisis que debería distinguir entre lo esencial y lo cultural, y me detengo en la pregunta: ¿En qué estudios sobre el Jesús histórico se basan las afirmaciones o negaciones de que algo se hizo o no? Afirmar que Jesús hizo (o no hizo) algo, requeriría, sin duda, un trabajo histórico para comenzar. En muchos casos, ese trabajo parece ausente.

La pretención aquí es señalar una suerte de "estado de la cuestión" de los estudios sobre el Jesús histórico en nuestros días ${ }^{2}$. Para ello, se presentan tres partes disímiles: (I) Una historia de cómo se ha llegado a la/s actual/es búsqueda/s del Jesús Histórico. (II.) una presentación de los artículos de una obra monumental, a Handbook for the Study of the Historical Jesus (2010) y (III.) un señalamiento más de los límites de esta obra, excesivamente "Primermundista".

Se calcula que en el siglo pasado se escribieron unos cien mil libros sobre Jesús de Nazaret, unos mil al año. Libros de lo más variados: novelas, unas más históricas y otras de pura ficción, libros espirituales, científicos con orientaciones diversas, algunos escritos por creyentes, otros beligerantemente en contra de la fé cristiana. Reflexión aparte merecería la increíble avalancha de informaciones sobre Jesús que circulan por Internet, sin ningún filtro de calidad y de acceso sumamente fácil.

Se ha podido decir, sin exageración alguna, que los estudios históricos sobre Jesús y los evangelios suponen el mayor esfuerzo jamás realizado por la razón crítica en el campo religioso. Sin embargo, en nuestros días se alzan voces manifestando que este estudio no tiene ningún interés teológico (Aguirre, 2015, p. 71).

Veamos, para empezar, cómo hemos llegado hasta aquí ${ }^{3 .}$

\section{I. ¿Cómo llegamos hasta el presente?}

\section{Tercera búsqueda}

Se suele hablar de la "tercera búsqueda"; aunque el esquema trifásico tiene un punto de partida discutible ${ }^{4}$ : no todos coinciden con el

\footnotetext{
${ }^{2}$ Es importante señalar que, precisamente, decir "nuestros días" marca - de entrada - un límite preocupante. Con mucha frecuencia, y en temas históricos del mundo antiguo ciertamente lo es, algo que ayer era "adquirido" bien puede ser "dudoso" mañana. Aquí radica - para muchos - el motivo de desaliento. Para otros, entre los que nos contamos, el desafío. Me permito un ejemplo: en varios trabajos - algunos los citaremos - se hace referencia a las parábolas, pero luego de estos, J. P. Meier publicó el tomo V de A Marginal Jew (2016), algo que, indudablemente, ha de tenerse en cuenta. Pero luego que Meier publicara su volumen, en 2014, Amy-Jill Levine publicó su desafiante "Relatos cortos de Jesús. Las parábolas enigmáticas de un rabino polémico" (Levine, 2014); Meier sólo cita de Levine un artículo de 2012 sobre el Buen Samaritano (cf. p. 227. n. 47).

${ }^{3}$ Tendremos particularmente en cuenta el texto recién citado de R. Aguirre para la breve presentación histórica (I.), y luego, sobre los diferentes temas que se van destacando, la obra editada por T. Holmén, S. E. Porter, Handbook for the Study of the Historical Jesus (2010) (II.). Esta obra colectiva permite tener una buena comprensión de la temática actual. La presentaremos en detalle, para lo cual sólo señalaremos el autor, artículo, tomo y páginas de este trabajo. Una obra en esta misma dirección, aunque más breve, puede verse en M. Bockmuehl (2001). Finalmente (III.) Presentaremos otros accesos al Jesús histórico no incluidos en este Handbook.

${ }^{4} \mathrm{El}$ autor ha cuestionado las "tres" búsquedas también en sendos artículos anteriores: "Historiografía, exégesis e ideología. La ficción contemporánea de las 'tres búsquedas' del Jesús histórico” (I y II) (2005, pp. 349-406) y XXXI/1 (2006, pp. 53-114); “The Fiction of the ‘Three quests'. An Argument for Dismantling a Dubious Historiographical Paradigm” (2009, pp. 211-253). Esta es - además - la tercera parte de su reciente trabajo: La invención de Jesús de Nazaret. Historia, ficción, historiografía (2018).
} 
término "tercera búsqueda" y algunos sólo hablan de "búsqueda" (Bermejo-Rubio, 2019). Si bien es cierto que la categoría "historia", entendida como "ciencia", es moderna, podemos señalar que ya desde el humanismo se multiplican las obras sobre Jesús. Influye en los movimientos de reforma (ss. XII-XIII), la búsqueda de solución a las guerras de religión (ss. XVI-XVII) e incluso en filósofos y la revolución francesa; la centralidad de "la humanidad de Jesús" en Francisco de Asís $^{5}$ o Teresa de Ávila ${ }^{6}$ son ejemplo de esto. Se ha de sumar a esto también a varios historiadores judíos que ya desde el s. XVI destacaron al Jesús judío.

A.- Pero un cierto convencionalismo académico destaca a Reimarus (1694-1768) como el comienzo por el intento de someter los Evangelios a un estudio crítico. Hace referencia al fracaso de Jesús y la recreación de los discípulos, por eso debe ser liberado del secuestro del Cristo de la Iglesia (cosa que también sostendrán Strauss, Harnack, Renan). Kähler fue el primero en distinguir entre Jesús de la historia y Cristo bíblico, o de la fé (1892). Albert Schweitzer (1875-1965) hace un balance decepcionante de todas estas investigaciones, centrándose especialmente en el "reino de Dios" (algo inminente y de alta moral). Lo que lo decepciona no es desde el escepticismo sino desde lo que ve como "lejanía" (en lugar de apertura hay estrecheces nacionales y confesionales). Algunos, siguiéndolo, lo presentan como ideal de humanidad (teología liberal) y otros más apocalípticos anunciando el reino. También debe ser liberado de los vaivenes de la historia. En este contexto, nos encontramos con Bultmann señalando el sentido teológico de los Evangelios y que la historia no es importante (sola fide). Aquí ubican algunos que ocurre el final de la Primera búsqueda.

B.- El planteamiento del Jesús histórico en los discípulos de Bultmann. Lo que se ha llamado No Quest, consecuencia de la crisis que provoca el "fin" de la "primera búsqueda", en realidad es algo que solo ocurre desde la perspectiva de Bultmann, porque en realidad, nunca dejó de haber búsqueda. Los hubo en el mundo anglosajón, pero también alemán, e incluso anti-judío ("Jesús ario", W. Grundmann) y francófono.

En 1953, E. Käsemann sostuvo que el escepticismo radical era insostenible: acceder al Jesús histórico es garantía del "extra nos" de la salvación (Käsemann, 1978, p. 176) ${ }^{7}$. Su criterio principal es el de "desemejanza", o ruptura con el ambiente judío... pretende así llegar a lo "propio" de Jesús. Pero así se llega a un Jesús sin raíces y en el que es la teología la que "marca la agenda". A esta nueva etapa se la ha llamado "nueva búsqueda".

C.- La investigación actual, o mal llamada "tercera búsqueda" (Third Quest). A partir de los años 80 empezó una "avalancha" de trabajos sobre Jesús. Parecen, Neill y Wright (1988) fueron los primeros en usar "Third Quest" (Neil y Wright, 1988; Wright, 1992,; Goodacre, 2007). Pero en realidad, habría que señalar que, la búsqueda nunca se interrumpió. Los estudios hoy son muy diversos y no hay uniformidad, sino autores que parecen cercanos a la "Old Quest", algunos cercanos a Schweitzer y otros a la "teología liberal”. El grupo más conocido, pero no el

\footnotetext{
5"Empéñense todos los hermanos en seguir la humildad y pobreza de Nuestro Señor Jesucristo (...) Recuerden que Nuestro Señor Jesucristo el Hijo de Dios vivo omnipotente (...) no se avergonzó y fue pobre y huésped y vivió de limosna", Primera regla IX,1-5. "Jesucristo, cuyas huellas debemos seguir” (XXII,12) (Asis, 1985)

${ }^{6}$ Vida 22; 27; 7 Morada 2; 6 Morada 7,6: “la sacratísima humanidad de Nuestro Señor Jesucristo (...) si pierden la guía que es el buen Jesús no acertarán el camino"... (Ávila, 1982).

${ }^{7}$ Un reconocimiento al profesor Ernst Käsemann por la desaparición de su hija Elisabeth en la dictadura en Argentina en la noche del 8 y 9 de marzo de 1977.
} 
más representativo, es el Jesus Seminar, un Jesús "desescatologizado y contracultural", pero no aceptado por la mayoría académica. Por tanto, algunass características de los estudios contemporáneos son:

- Se ha superado el escepticismo radical y se confía más en los Evangelios sin dejar de tener en cuenta sus especificidades.

- Es tenida en cuenta la literatura apócrifa (especialmente Tomas y Pedro) y Nag Hammadi (especialmente en alguna escuela).

- El judaísmo de tiempos de Jesús era sumamente plural (el criterio de desemejanza desarraigaba a Jesús).

- Se contextualiza en el imperio romano en un entramado socio-político.

- Se utiliza una investigación interdisciplinar (lenguaje, arqueología, ciencias sociales...) (Aguirre, 2015).

Lo cierto es que, se ha producido una "avalancha" de estudios sobre Jesús, y a partir de ello también sobre los Orígenes del cristianismo ${ }^{8}$. A nivel simbólico, se pueden tener en cuenta dos elementos que son representativos de la novedad: la incorporación del artículo "Jesús" (y también el de "Iglesia primitiva") en el Nuevo Comentario Bíblico San Jerónimo (1990, ausente en la primera edición, 1968); y a aparición desde 2003 del Journal for the Study of the Historical Jesus (2 apariciones al año hasta 2009 y desde entonces 3 [aunque a veces hay números dobles]).

\section{Diversas imágenes de Jesús}

Las “imágenes" de Jesús, fruto de los estudios, son variadas y han llevado a muchos al desaliento.

a. Un cínico itinerante contracultural (Crossan, 2010)

b. Un sabio espiritual

c. Un hasid judío sanador (Vermes, 2012)

d. Un fariseo

e. Un profeta escatológico

f. Un profeta milenarista (Allison, 2010)

g. Un "mago" / sanador (Smith, 2010)

h. Un renovador escatológico de Israel (Theissen, 2010)

i. Un revolucionario no violento (Horsley, 2010)

j. Un mesías liberador fracasado

k. Un judío marginal (Meier, 1991)

1. Un judío de Galilea

\section{Fuentes para acceder al Jesús histórico}

a. Q [o, según la hipótesis de Farrer (1955) Mt----> Lc] ¿hay diferentes etapas?

b. Tomás (y los manuscritos de Oxyrrinco $1,654$ y 655$)^{9}$

c. Marcos (¿etapas de Marcos? $)^{10}$

d. M / L (dificultades) ${ }^{11}$

e. Juan (¿evangelio espiritual? $)^{12}$

f. Evangelio de Pedro (¿fecha?) ${ }^{13}$

g. Pablo (¿concentración narrativa?) (De la Serna, 2019)

${ }^{8}$ Un reconocimiento a la Facultad de Teología de la UCA (Buenos Aires) que desde los comienzos de los 70 tuvo la materia "Orígenes cristianos" (originalmente a cargo de R. Trevijano y C. Giaquinta) en su currícula. Es, por ejemplo, el título del libro póstumo de G. Vermes (2012): Christian begginings, from Nazareth to Nicaea (AD 30-325) (2012; 2013) ${ }^{9}$ Tanto de la supuesta fuente Q como del Evangelio de Tomás se ha propuesto, por ejemplo, que hay - en ambos casos - tres etapas de redacción. En el primero de los casos puede verse Kloppenborg (2005), y sobre el EvTh, Trevijano (1997). Sin embargo, ha de tenerse en cuenta que no todos los autores coinciden en la existencia de "Q"; la posición de A. Farrer (1955), por ejemplo, vuelve a tener adeptos.

${ }^{10}$ También se ha pensado en la posibilidad de que el evangelio de Marcos se haya compuesto en etapas: se ha hablado de proto-Marcos; hay quienes entienden que Lucas conoce una versión más breve de Marcos; de allí la omisión del relato de la mujer sirofenicia (Mc 7,24-30) que parecería razonable que Lucas lo incorporara vistos sus intereses teológicos. Es evidente el añadido posterior de los relatos de apariciones del resucitado ante el final aparentemente inesperado de Marcos (16,9-20).

${ }^{11}$ Suele llamarse L o M a los textos (no necesariamente de una sola fuente) propios de Lucas o de Mateo respectivamente que no provienen de Mc ni de Q. Sin embargo, un problema es, por ejemplo, ¿cómo saber si algo proviene de una de estas fuentes o que, por el contrario, el otro evangelio rehusó incluirlo? Un ejemplo sencillo puede encontrarse en el doble texto del varón que pierde una oveja y la mujer que pierde una moneda en Lc 15,4-7.8-10. Mateo sólo incluye el relato de la oveja perdida (18,12-14). El relato de la mujer que pierde la moneda, ¿ fue incorporado por Lucas de L u omitido de Q por Mateo? La frecuencia de textos paralelos de un varón y una mujer de Q invita a pensar la segunda opción, del mismo modo que una mayor relativización del lugar de la mujer en la comunidad propio de Mateo invita en el mismo sentido a entender la omisión.

${ }^{12}$ Juan y Marcos "son dos representaciones diferentes de la historia de Jesús" (Zumstein, 2019, p. 136).

${ }^{13} \mathrm{Sin}$ duda la dependencia o no del EvPe de las fuentes sinópticas será decisivo (como es el caso del EvTh, aunque las etapas redaccionales relativicen el tema). 
h. Mientras el Jesús Seminar habla de Tomás como del "quinto Evangelio", B. Pixner usa esa misma imagen para aludir a la topografía de Israel (Funk and the Jesus Seminar, 1993; Pixner, 1992).

Acuerdos sobre Jesús histórico (aunque...) ${ }^{14}$

La tendencia inveterada a domesticarle, haciéndole uno de nosotros, queda superada cuando le situamos en su propia concreción histórica (Johnson, 2004).

- Bautizado por Juan

- Anunció el Reino de Dios y solicitaba fé en ese reino

- Experiencia religiosa profunda

- Se dirigió a todo el pueblo de Israel, no a selectos, y con preferencia a los estigmatizados social y religiosamente

- Junto a él se reunió un grupo de seguidores

- Promovió un movimiento que le atribuyó especial autoridad, suscitando esperanza, especialmente en Galilea.

- Hizo sanaciones y expulsó demonios

- Se mantuvo siempre fiel al judaísmo

- Asumió un aspecto marginal en su vida

- En Jerusalén, un signo en el Templo resultó decisivo

- Fue crucificado bajo Caifás y Pilato en alianza contra él

- Su movimiento pervivió después de su muerte; algunos afirmaron su resurrección

\section{Diversos puntos de vista, cuestiones, acuer- dos y diferencias}

Avances y límites

a. Somos historiadores de la tradición de Jesús, somos contadores de historias. No podemos más que aspirar a crear una narrativa hipotética que sea más persuasiva que las narrativas contrarias (Allison 2010).

b. La "Tercera búsqueda" está definitivamente en una etapa de inflexión, y debe ser reemplazada por una "Cuarta búsqueda" que se concentrará en el enfoque de Jesús, su programa y su visión (Baasland, 2010).

c. La discusión de los criterios ha tomado el camino de las fuentes literarias al material tradicional que está cerca de Jesús y a la evaluación de este material. Un camino intermedio entre el escepticismo histórico y una confianza excesiva en la fiabilidad histórica de los evangelios (Becker, 2010b).

d. Algunos no estamos interesados principalmente por la fé cristiana (aunque la distinción entre teólogos e historiadores no sea hoy tan clara). Hay preguntas que debemos seguir haciendo: por qué crucificado, su judaísmo, etc. (Charlesworth, 2010).

e. El Jesús histórico es una lectura de toda la evidencia disponible que nos permite explicar, en términos religiosos, el surgimiento del cristianismo a partir del judaísmo del Segundo Templo. (J2T). (Chilton, 2010a).

f. El establecimiento del contexto mediante un modelo interdisciplinario e interactivo de antropología intercultural en el nivel más general, la historia judeo-romana en el nivel intermedio y la arqueología galileana en el más específico; a partir de ahí nos preguntaremos ¿cómo determinar los datos del Jesús histórico? (Crossan, 2010).

g. Se señalan tres elementos: Jesús reclamó la fé desde el comienzo; importancia de la fase oral de las fuentes; buscar al Jesús judío (Dunn, 2010).

h. Abandonar suposiciones basadas en la teología. La comprensión de los evangelios como

\footnotetext{
${ }^{14}$ Ver Aguirre (2015, pp. 86-87); pero - como se verá - otros autores proponen acuerdos más extensos (pero que no parecen tan “acordados", cf. Charlesworth I ,116-123 que propone 54 temas).
} 
interpretación oral y en términos de memoria social conduce a un mayor sentido tanto de la continuidad como de la discontinuidad entre Jesús en su movimiento en el contexto histórico y las diversas narraciones y discursos del Evangelio en sus respectivas situaciones. El contexto histórico y los Evangelios nos impiden volver a preconceptos standard (Horsley, 2010).

i. Es preciso comprender los fundamentos metodológicos sobre los cuales se han construido los retratos y las cuestiones teóricas que impulsan la búsqueda (Kloppenborg, 2010).

j. Tenemos criterios principales (5: vergüenza, discontinuidad, testimonio múltiple en las fuentes o formas, coherencia y rechazo y ejecución de Jesús) y secundarios (5: huellas arameas, ambiente palestino, vivacidad de la narrativa, tendencias de la tradición sinóptica y presunción histórica) para acceder a dichos o hechos. No debemos sentir que los resultados de nuestra búsqueda serán inusualmente frágiles o inciertos; no son más frágiles o inciertos que muchas otras partes de nuestras vidas (Meier, 2010).

$k$. La tarea central de la investigación de Jesús es reconstruir la teología de Jesús e identificar su relación con sus actividades. Los textos también son nuestra fuente principal para reconstruir algunos de los hechos sobre la vida de Jesús, ya que la mayoría de los textos tienen un carácter explícitamente referencial (Pokorný, 2010).

1. Trata de delinear los criterios para la investigación de la lengua griega sobre la autenticidad de los dichos del Jesús histórico; constituye un esfuerzo para reintroducir los criterios del griego en la investigación histórica de Jesús al demostrar tanto el método como los resultados (Porter, 2010).

m. Intentar una reconstrucción comparando los sinópticos e incluso el Evangelio de Juan sigue siendo una empresa prometedora; los evangelios canónicos imprimen a sus lectores una imagen clara (in nuce) de Jesús de Nazaret (Riesner, 2010).

n. El éxito de la investigación se ha basado en los nuevos métodos introducidos que logran efectos duraderos; a pesar de la introducción de nuevos métodos para proporcionar correctivos, rellenar los puntos ciegos, deshacer los excesos, etc. Pero los nuevos métodos que simplemente rechazan o ignoran la historia de la erudición han resultado ser, en general, inválidos. Creo en la centralidad de Q (Robinson, 2010).

o. El Jesús de la historia es de hecho solo el Jesús reconstruido por la disciplina académica conocida como historia, no lo que podríamos llamar el Jesús "real". Y esto significa que a pesar de las reservas que se ven en este punto entre los teólogos (incluidos algunos exégetas), un enfoque secular, es decir, uno realizado desde una perspectiva puramente histórica, me parece legítimo y posible. No es sensato olvidar que el judaísmo del s. I fue polimorfo y no se identifica con el judaísmo rabínico (Schlosser, 2010a).

p. No sólo es tema metodológico sino también epistemológico (el sentido dado a los datos: lo que guía las elecciones académicas). Un enfoque feminista crítico requiere que pongamos en primer plano los supuestos epistemológicos que guían las elecciones académicas de metodologías, cómo procedemos a implementar métodos particulares y cómo nos ponemos en contacto con la imaginación histórica y las ideologías legitimadoras que determinan nuestras elecciones de metáforas y modelos reconstructivos (Schussler, 2010).

q. Analiza la posibilidad de certeza histórica en la investigación de Jesús (mirando el problema de la crítica de las fuentes históricas; el problema del relativismo histórico y el problema de la extrañeza histórica), luego mira la posibilidad de certeza religiosa en la fé cristiana, deteniéndose en la orientación al cuadro bíblico de 
Jesús, el intento de garantizar la autenticidad de la imagen de Jesús, la reducción de la imagen de Jesús en la teología kerigmática, la comprensión simbólica de la imagen de Jesús, reconociendo el carácter hipotético de todo conocimiento y fé y el sentido para el elemento incondicional en el conocimiento y la fé (Theissen, 2010).

\section{Consideraciones}

a. Lo que propongo aquí, es sugerir que una de las razones por las que se escribieron los evangelios fue para confrontar los cargos, las manchas y las características embarazosas aplicadas a Jesús (Brown, 2010).

b. La Historia de las formas: ha proporcionado una verdadera base de datos sobre Jesús que algunos han considerado los bloques de construcción para usar en la elaboración de una imagen del Jesús histórico (Hultgren, 2010).

c. La Historia de la tradición, es un aliado de la verificación histórica más que su enemigo, ya que ayuda a identificar las opciones editoriales del evangelista y la estrategia narrativa general a nivel macro y, por lo tanto, ayuda al proceso histórico (Osborne, 2010).

d. Solo tres criterios parecen estar en el corazón de la mayoría de los tratamientos (de disimilitud, de fuentes múltiples y de coherencia). Debería prestarse más atención al desarrollo de métodos históricos que se encuentran al menos en plataformas conceptuales similares con otras disciplinas de estudios antiguos (Porter, 2010).

e. La plausibilidad histórica de las tradiciones conduce a un "Jesús histórico" que se refleja a través de la perspectiva subjetiva de las personas humanas contemporáneas, o que puede interpretarse desde su perspectiva subjetiva, sólo ese puede ser relevante para las personas de hoy (Nicklas, 2010b).

f. Comprensión de los sistemas sociales: $\mathrm{Si}$ los autores antiguos comunicaban significados a sus audiencias, la única manera de entender lo que esas audiencias entendieron es entender sus sistemas sociales. De lo contrario, las lecturas de las fuentes serán necesariamente anacrónicas y etnocéntricas. Los enfoques de las ciencias sociales para la investigación de Jesús se han desarrollado para evitar esas trampas (Malina, 2010).

g. La nueva crítica literaria y la investigación de Jesús difieren en sus enfoques básicos de los evangelios. Para los investigadores de Jesús, el desafío es analizar los evangelios en busca de rastros de otra cosa: el Jesús histórico. Para los nuevos críticos literarios, el desafío es apreciar los evangelios en sí mismos y en relación con sus múltiples audiencias. Para los primeros los evangelios son medios, para los últimos, son fines (Struthers, 2010).

h. Centralidad de la memoria; el análisis de la memoria pone el aspecto adecuado en el dato central de la investigación, las tradiciones del Evangelio. Son artefactos de la memoria; han circulado a lo largo de caminos de memorización; y al encontrar su camino en el medio escrito, han navegado sobre la mayor crisis de la memoria. Los evangelios, podríamos decir, son los pozos profundos de la memoria de los primeros cristianos (Kirk, 2010).

i. La evaluación histórica de los textos del Evangelio, sea cual fuere, y la reconstrucción del fondo de la fuente, deben ser históricamente plausibles. Este es un punto importante del criterio de plausibilidad histórica (cf. criterios de autenticidad) que refuerza el cierre del debate sobre dónde debe estar la carga de la prueba (Winter, 2010).

\section{Búsqueda de Jesús}

a. Tal vez solo haya dos búsquedas con muchas formas: la búsqueda del Jesús no histórico y la búsqueda del Jesús histórico. Ambos están 
sin terminar. Indudablemente, muchos seguirán la búsqueda del Jesús no histórico, en la creencia de que el Jesús no histórico es el verdadero Jesús. Pero un Jesús de la fé separado de la historia es un producto de la imaginación. Para los cristianos y los de otras religiones, la realidad de Jesús no puede ser separada de la historia (Brown, 2010).

b. Señalaré algunas características de la investigación de Jesús que creo que prevalecerán en el futuro. Solo pronunciaré dos "profecías", bastante amplias y generales: A. Los evangelios serán vistos como una evidencia generalmente confiable (no totalmente) de Jesús. B. La investigación de Jesús usará un método más holístico. La imagen total o "Gestalt" de Jesús debe estar relacionada con la forma en que entendió su misión y con lo que estaba por hacer. Y la clave para los objetivos de Jesús es su autocomprensión, su "cristología", por así decirlo (Holmberg, 2010).

c. ¿Qué es la historia?, ¿qué es un Jesús histórico?, y ¿qué papel debe desempeñar ese Jesús histórico en el currículo teológico? La iglesia en sí vino de la trayectoria que L. Hurtado presenta. Y muchos de los estudios históricos de Jesús hoy se ajustan a los parámetros esbozados por él, mientras muchos no cabrían. Esas representaciones narrativas de Jesús que no encajan en esa cuadrícula tampoco encajarían en un plan de estudios teológico para enseñar una comprensión tradicional de Jesús (McKnight, 2010).

d. Mientras que el Norte o el Oeste parecen estar empeñados y comprometidos con interminables "búsquedas" o "investigaciones" en el Jesús histórico, el Sur prefiere dedicar su energía y recursos psíquicos, intelectuales y espirituales a la "recepción" de este mismo Jesús histórico (Okure, 2010).

e. La búsqueda de Jesús es búsqueda ideológica; esos intereses pueden ser diferentes: teológicos, anti-eclesiásticos, éticos, políticos, culturales-religiosos, psicológicos, filosóficos... Incluso si Jesús solo "existiera" siempre en este espacio disputado en una forma narrativa muy disputada, la crítica mutua es vital (Marsh, 2010).

f. Auto-afirmación de Jesús; ¿hay o no continuidad o "traición” entre el Jesús histórico y el Cristo de la fé (dogmas)? ¿Hay una cristología implícita en Jesús o no? Pareciera que sí (Back, 2010).

g. Schalom Ben-Chorin: "La fé de Jesús nos une, la fé en Jesús nos separa”. Hay muchos avances, y todavía otros límites; acentuación de la fé judía de Jesús: la búsqueda del Jesús histórico es fundamental para el diálogo judeo-cristiano, pero hay que ir más allá (Hagner, 2010).

h. Diferentes imágenes de Jesús: la honestidad requiere el reconocimiento del hecho de que incluso el Cristo del kerygma no es, estrictamente hablando, el verdadero Jesús, sino el resultado de una selección de hechos. Jesús tiene muchas caras (Heyer, 2010).

\section{Preguntas actuales}

a. El cinismo; es claramente discutible poner en el mismo nivel el judaísmo y el cinismo en tiempos de Jesús (Downing, 2010).

b. Jesús desafió varias halakha contemporáneas. El Jesús más "plausible" es el que discute, discute y discute el significado de las escrituras de Israel, porque también fueron sus escrituras (Moyise, 2010).

c. Cristología implícita: partiendo de lo que "sabemos" de Jesús, la cristología implícita ahora desempeña un papel positivo, ya que considera las implicaciones de la misión de Jesús y arroja más luz sobre los contornos de su identidad (Broadhead, 2010a).

d. Hay un parteaguas con el judaísmo, ¿qué lo ocasionó? ¿Jesús? Es importante comprender la causa de la muerte y los conflictos con los contemporáneos. Jesús permaneció dentro de la órbita de un "judaísmo común", sus 
actitudes y acciones empujaron (posteriormente) esos límites hasta el punto de que incurrió en una violenta oposición de otros judíos (Bird, 2010).

e. Hay diferentes identidades de Jesús: profeta, sabio, sanador, mesías y mártir (Evans, 2010).

f.Hay elementos de semejanza y de diferencia con Qumrán: el discipulado, la halakha, el mandamiento del amor, la escatología, el maestro de justicia (Kuhn, 2010).

g. "Sin Q"; hay dos grupos: Jerusalén y Pablo. Si Marcos (paulino) da una imagen paulina de Jesús, lo sospecharemos. Si da una imagen no paulina, parecerá una tradición no digerida, y por lo tanto debe ser acreditado con cautela. En general, lo que va en contra del pensamiento de un autor debe ser tratado con seriedad; cualquier cosa que le parezca embarazosa es probablemente cierta (Goulder, 2010).

h. La prioridad de Marcos no impide mirar la teoría de las fuentes (crítica de las sinopsis usadas): uno no puede examinar los fenómenos sin romperlos en el acto de crear una sinopsis para estudiarlos (Dungan, 2010).

i. El papel del arameo es fundamental para reconstruir (partes de $\mathrm{Mc}$ y $\mathrm{Q}$ ) y comprender la enseñanza de Jesús, aunque no haya sido - salvo excepciones - muy utilizado por los autores contemporáneos (Casey, 2010).

j. La hipótesis posmoderna: el estudio histórico solo puede articularse en la forma de un discurso narrativo que encuentra su contenido y lo imagina o lo inventa. White no niega la existencia de hechos históricos como se dan; pero estos hechos solo pueden hacerse significativos al tejerlos en una imagen del pasado que, una vez más, presupone una noción de totalidad. Esto puede llevar al respeto por la contingencia, la fragilidad y la sublimidad de la historia y al "espíritu" de mirar "objetos" con paciencia, autocrítica y una profunda conciencia de las complejidades de los discursos de los que formamos parte (Mayordomo y Ben Smit, 2010).

k. Hay material negativo y positivo, el evangelista y los adversarios (el ejemplo de las expulsiones de demonios, o el hijo obstinado de Dt 21,20). El Evangelio es historia escrita desde los perdedores (Brown, 2010).

\section{Problemas}

a. ¿Judío y/o helenista? En el marco del judaísmo dentro del helenismo, uno debe preguntarse dónde encaja Jesús. Como lo demuestra la historia de los estudios anteriores, en un sentido, la búsqueda en curso de Jesús, en términos de su relación con las culturas que la rodean, siempre ha reconocido y explorado el carácter judío de Jesús (Porter, 2010).

b. Transmisión oral de la tradición; es esencial darse cuenta de que la tradición verbal es parte de un panorama más amplio de la tradición. La predicación no era simplemente una cuestión de transmitir palabras y hechos separados de Jesús, sino de hablar de la historia como historia (Byrskog, 2010).

c. Se presenta a los fariseos, saduceos, esenios y herodianos teniendo en cuenta especialmente a Josefo (y sus diferencias dentro de sus mismas obras) (Nodet, 2010).

d. "El hijo del hombre" en el judaísmo: la representación del Hijo del Hombre en los evangelios comparte con los textos judíos contemporáneos la expectativa de una figura del salvador celestial, y también lo pone en el papel de juez. No hay razón, en principio, por la cual Jesús no debería haber compartido tales expectativas, basándose en la especulación en curso sobre la visión de Daniel (Collins, 2010).

e. Hay diferencias entre qué entienden por apocalíptica y apocalipticismo Collins $y$ Rowland; la literatura apocalíptica judía no puede entenderse aparte de la cosmología peculiar de 
la teología del Templo de Israel y las experiencias religiosas que ofrece (Fletcher-Louis, 2010b).

f. Hay que resaltar la importancia del antijudaísmo: que escritos del NT hayan sido utilizados de manera anti-judía no significa que los escritos lo sean, para lo cual es necesario un análisis histórico, social y retórico (Johnson, 2010).

g. Josefo aporta no solamente los elementos históricos (que deben ser cuestionados en la medida de lo posible), también su arte compositivo y sus lecturas bíblicas que no suelen ser tenidas en cuenta (Mason, 2010).

h. Con respecto a los escritos rabínicos, se ha de tener en cuenta las cuatro formas principales de la literatura rabínica: halakhah, aggadah, parábolas y objetivos (Instone-Brewer, 2010).

i. La sinagoga y el/los Sanedrín en el S.I: La sinagoga y el Sanedrín eran instituciones religiosas asociadas con el judaísmo anterior a los 70, pero eran muy diferentes entre sí en su naturaleza, función y operación. Lo que nuestra investigación mostró fue que muchos puntos de vista populares sobre ellos, que aún se encuentran en la literatura sobre el cristianismo primitivo, no tienen una base histórica o son, al menos, problemáticos (Grabbe, 2010).

j. Juan el Bautista: hay, en general, dos Juanes representados en el Nuevo Testamento: uno que está solo y otro que está al lado de Jesús. Con alivio notamos que los dos no se parecen. Parece plausible suponer que Juan el Bautista vio su actividad bautismal en la tradición bíblica de (Isaías y) Malaquías, y de ese modo volver a representar el papel del profeta Elías como el precursor del "día grande y terrible" cuando Dios estaba "por venir". La interpretación cristiana pudo vincularse con esta autodefinición, pero tuvo que "reorganizarla" para integrarla en la secuencia escatológica que se había desarrollado después de que Jesús entró en escena (Backhaus, 2010).

k. Una lectura historiográfica: (1) describe las presuposiciones literarias e históricas de la composición de la literatura historiográfica en este período. Estos están determinados por el período helenístico, la cultura y la literatura. (2) Presenta desarrollos literario-históricos significativos y representantes literarios de la literatura historiográfica en el llamado período imperial temprano (ca. 30 a.C.-ca. $120 \mathrm{CE}$ ), en el griegohelenístico, romano y las primeras esferas judías. (3) Discute en qué medida los primeros textos cristianos, especialmente la literatura del evangelio, pertenecen al marco de la historia literaria de la historiografía helenística (Becker, 2010a).

\section{Tradiciones}

a. Marcos: El uso cuidadoso del Evangelio de Marcos enriquecerá nuestras reconstrucciones históricas (Dewey, 2010).

b. "Q": entre Q y Jesús hay elementos de continuidad y discontinuidad. La clasificación de dónde deben identificarse sigue siendo la tarea de todos aquellos comprometidos con la llamada búsqueda del Jesús histórico (Tuckett, 2010).

c. "M": Estos materiales no revelan información histórica novedosa sobre Jesús de Nazaret que aún no está presente en las fuentes principales de Mateo. Pero sí subrayan el uso característico del motivo del Reino de Dios, confirman el carácter escatológico de la enseñanza de Jesús y el hecho de que formó una comunidad de discípulos, e ilustran el sabor completamente judío de su enseñanza y piedad (Senior, 2010).

d. Lucas-Hechos: Hay buenas razones para pensar que Lucas estuvo en contacto con las tradiciones de Jesús al menos a principios de la década de los 50, que estuvo en contacto con testigos oculares y que escribió sobre la base de una investigación considerable (Nolland, 2010).

e. Jesús no-sinóptico: La integración de la recepción de Jesús en la forma concentrada de abreviaturas narrativas es impresionante, y nos 
dice mucho sobre el pensamiento de Pablo. Debemos escuchar a Juan, el narrador de la historia de Jesús, así como a Pablo y las historias extra canónicas de Jesús (Labahn, 2010) ${ }^{15}$.

f.Juan es un Evangelio independiente, y vale la pena tomar en serio la afirmación de que se basa en un testimonio independiente (Smith, 2010).

g. Epístolas: por ejemplo, Pablo reconoce a Jesús enseñando sobre el apoyo de los apóstoles, pero él no lo toma como una orden para cada situación, sino como un privilegio que puede renunciar por el bien del evangelio y en el servicio de Jesús, a quien le corresponde seguir (Wenham, 2010) .

h. Tomás: Cada uno de los 114 dichos en Tomás debe ser investigado por razones críticas para establecer su proximidad a Jesús. Sólo de esta manera podemos explorar completamente la conexión entre Jesús y Tomás y establecer el lugar de Tomás en el paisaje del cristianismo primitivo (Broadhead, 2010b).

i. Otros apócrifos: la mayoría de ellos no aportan nada que pueda llevarnos más allá de lo que sabemos de los textos canónicos o prestar nuevos acentos al retrato del Jesús histórico (Nicklas, 2010a).

j. Primeros padres: la cosecha de tradiciones posiblemente auténticas de Jesús en la literatura patrística que investigamos es bastante escasa. El resultado consiste en una pequeña cantidad de palabras de Jesús que "no agregan mucho a la imagen general, su credibilidad como dichos de Jesús depende en gran medida de su compatibilidad con las tradiciones sinópticas más familiares” [Dunn] (Rouckema, 2010, p. 2123).

k. Escritos clásicos y judíos: la mayoría de las tradiciones clásicas y rabínicas sobre Jesús surgen en un polémico Sitz im Leben, y contribuyen poco a nuestro conocimiento del Jesús histórico (Van Voorst, 2010).

\section{Fundamentos}

a. ¿Jesús existió? Los dos tipos de investigación diacrónica y el aspecto hermenéutico de la reconstrucción histórica implican que Jesús existió, porque desde nuestro propio horizonte esta es la explicación más satisfactoria de cómo surgió y se desarrolló la tradición de Jesús (Byrskog, 2010).

b. Trasfondo topográfico (topografía geofísica, cultural y de la tradición). Hemos llegado a comprender que Jesús y sus seguidores no vieron un paisaje ya objetivo e interpretado; percibieron su topografía no sólo en términos de su característica geofísica sino también en términos de cómo se había enmarcado cultural y tradicionalmente para ellos. Polibio aconsejó que la historiografía debe incluir, entre otras cosas, "el estudio de ciudades, lugares, ríos, lagos y, en general, todas las características peculiares de la tierra y el mar y las distancias de un lugar a otro" (Charlesworth, 2010).

c. Trasfondo: algunos documentos demuestran que las narraciones de Jesús del Evangelio se ubican directamente dentro de la tradición judía palestina. La conciencia de los documentos literarios puede influir no sólo en la cuestión del Jesús histórico, sino también en nuestra comprensión de la formación de la tradición del evangelio y de la obra redaccional de los evangelistas (McNamara, 2010).

d. Trasfondo: clima sociopolítico; Reed sostiene (más claramente que Schottroff y Stegemann) que la fundación de dos centros urbanos en Galilea cambió la situación económica

\footnotetext{
${ }^{15}$ En la conferencia que da origen a este escrito, intenté decir “tener en cuenta las 7 cartas de Pablo más que las 6 deutero-paulinas" y por error afirmé "las 6 cartas de Pablo y las deutero-paulinas". Sirva este espacio para la corrección de ese error.
} 
en detrimento de la población rural; admito de buena gana que este cambio en el clima político y social de Galilea brinda una plausibilidad adicional al surgimiento del movimiento de Jesús (Stegemann, 2010).

e. La cronología de Jesús: nacimiento, comienzo y duración del ministerio y muerte de Jesús (Hoehner, 2010).

f. Nacimiento: evidencia externa, personajes y temática (France, 2010).

g. Muerte: ubicación en el contexto histórico romano, y responsabilidad de la élite judía. Jesús ha de haber anticipado su muerte (lo que implica reflexionar sobre ello) (Green, 2010).

h. Resurrección: tumba vacía, apariciones y resurrección (= fin del mundo) (Perkins, 2010).

i. Familia, amigos y enemigos: Lo que es sorprendente acerca de las relaciones que hemos encuestado es su carácter de múltiples estructuras. La familia se redefine. Los asociados más cercanos de Jesús son lentos para comprender la naturaleza de su misión y la naturaleza de su identidad ante Dios. En cuanto a sus enemigos, aunque como grupos de personajes se alinean contra él, los miembros de estos grupos son capaces de una valoración y asociación más positiva con Jesús (Green, 2010).

j. Lengua(s) de Jesús: El multilingüismo del primer siglo, Palestina incluida, indica un escenario lingüístico mucho más complejo que el que se presenta a menudo, y apunta hacia Jesús, junto con muchos otros de su tiempo, que tienen competencia multilingüe, incluyendo al menos arameo y griego (Porter, 2010).

k. Auto-comprensión de Jesús: Se entendió a sí mismo como el representante definitivo y decisivo de Dios. Y así podemos decir que "Jesús tuvo una autocomprensión mesiánica, pero sin recurrir al título 'Mesías'"; Jesús testificó en el interrogatorio ante el Sanedrín y posiblemente también en el interrogatorio ante Pilato sobre su autocomprensión como representante escatológico de Dios y, por lo tanto, reclamó la dignidad mesiánica (Kreplin, 2010).

1. El mensaje, los milagros: por más segura e importante que pueda ser la tradición del milagro, la visión presentada al mundo de habla inglesa por $\mathrm{CH}$ Dodd de que las historias de milagros son periféricas al kerygma, que permanece intacto, no se puede sostener a la vista de la evidencia. En cambio, esta apunta a que los milagros son fundamentales para cualquier reconstrucción legítima del Jesús histórico, incluyendo cómo se entendió a sí mismo (Twelftree, 2010).

m. El mensaje, las parábolas: Presentan facetas de su mensaje, provocando al oyente, y lector de los evangelios de hoy, a reconsiderar sus puntos de vista con respecto a Dios, el reino de Dios y las expectativas de Dios, y ver diferentes maneras de interpretar esos puntos de vista. Si se quiere hablar del genio de Jesús, el ser humano, deberá incluir una referencia a su capacidad para contar parábolas y contar las que él hizo (Hultgren, 2010).

\section{Jesús e Israel}

a. Jesús y Dios: la singularidad de la visión de Jesús dependía de su convicción de la cercanía del reino de Dios. Es decir, hubo una dimensión explícitamente "escatológica" en el uso de "Padre" por parte de Jesús (Thompson, 2010).

b. El Shabbat: el no creó una nueva novela jesuana halaquika del sábado, por ejemplo, interpretando el mandamiento del sábado de una manera nueva o extendiendo los principios halájicos actuales. En cambio, la base de la ėłovoía jesuánica era la convicción de tener una conciencia inmediata de la voluntad de Dios y de estar en "los asuntos del Rey" (Back, 2010).

c. El Templo: A pesar de los diferentes enfoques hacia el templo dentro de la iglesia primitiva y a pesar de la gama bastante frustrante de 
desacuerdos en la evaluación académica moderna del acto y los dichos del templo de Jesús, no obstante, hay buenas razones para concluir esta revisión de la reciente investigación con una afirmación de que el acto de Jesús en el templo y los dichos relacionados, siguen siendo cruciales para cualquier representación del mensaje de Jesús de Nazaret y su comprensión de su propia misión (Ådna, 2010).

d. El Shemá le proporcionó a Jesús una lente para ver la Torá, la identidad del pacto y ciertos conceptos críticos como la bondad. Entendido de esta manera, el Shemá forma un tema clave en la enseñanza de Jesús (Huat Tan, 2010).

e. La Pureza: tomar el camino de Jesús con lo ritualmente impuro como punto de partida ha abierto una nueva puerta para comprender el pensamiento de la pureza de Jesús y aún más. También nos ha permitido ver qué problemas están involucrados, cómo reunirlos y cómo son relevantes para la pregunta principal (Holmén, 2010)

f. La Ley: No puede reducirse a un programa político social, ni a un individualismo apolítico relacionado principalmente con la expiación individual, ni a las enseñanzas de un sabio carismático, sin ignorar gran parte de la tradición primitiva. La generosidad radical que extendió esta invitación a todos sin condiciones previas estableció direcciones que permitirían a algunos argumentar que, en contextos nuevos, algunas leyes de la Torá deben ser anuladas permanentemente y dejadas de lado, una postura aún no evidente en lo que parece derivar del Jesús histórico, ni requerido por ello (Loader, 2010).

g. La Tierra Santa: En una perspectiva continua, se puede leer Mt 5: 5 como una interpretación válida de la misión y el mensaje del reino de Jesús, extendiendo la promesa de Dios a Israel (tierra y gente) a aquellos mansos, "nuestro grupo", que serían seguidores (Wenell, 2010). h. Los pecadores y marginados: los contactos de Jesús con los pecadores y los marginados y mujeres, y su alarde de esos contactos, indicaban a su movimiento cómo Dios estaba extendiendo el alcance de la pureza a través de Israel (Chilton, 2010b).

i. El Israel escatológico: Si un pueblo conforme a la expresión escatológica de la voluntad de Dios ya estaba llegando a existir, entonces la restauración de Israel ya era en ese grado una realidad, una realidad efectuada por Juan y extendida por Jesús. Sin embargo, si este reino es, en primer lugar, éticamente constituido, todavía se da a una nación, una nación a través de la cual se afirmaría la soberanía de Dios sobre toda la creación. Como aquellos que dicen ser seguidores de Jesús y herederos de los privilegios que se les ha otorgado debido al juicio de Israel, los cristianos todavía deben enfrentar las implicaciones teológicas, sociales y políticas del hecho de que los objetivos de Jesús se centraron en la restauración nacional de Israel (Bryan, 2010).

j. Satán: La derrota de Satanás y compañía significó que las fuerzas del mal ya no tenían un dominio absoluto sobre la destrucción de la humanidad. En esto, la interacción de Jesús con Satanás y los demonios mostró que, con la victoria en la batalla, había llegado un poderoso testimonio de la victoria y la salvación (Bock, 2010).

k. Apocalipticismo: Sin duda, hay formas en que Jesús, el visionario apocalíptico, fue inusual, distintivo, único. No está registrado que haya tenido visiones en sueños. ¿Por qué? ¿Es esto irrelevante? Si hay una experiencia mística iniciática en la vida de Jesús según los evangelios, no es la que podemos esperar: ascender al cielo. Más bien, en el Bautismo, el Espíritu de Dios desciende a Jesús. Con una nueva perspectiva emergente sobre la apocalíptica, una que coloca la experiencia en su lugar legítimamente central, ahora hay una nueva oportunidad para 
comprender mejor el carácter histórico de Jesús (Fletcher-Louis, 2010a).

\section{Fuera del "Primer Mundo"}

Después de una presentación histórica (Parte I) y una vez señalado un "estado de la cuestión" valiéndonos del Handbook (Parte II) quedan abiertas una serie de preguntas. Tanto este trabajo, como el - también citado - Cambridge Companion sólo recurren a autores del "Norte", con la excepción de Teresa Okure, de Nigeria, en ambas obras, en sendos trabajos "al caso". Ahora bien, aunque pareciera centrado en el "Primer mundo" eso también es relativo. No hay autores de toda Europa. Charlesworth (2020) dice que "gracias a la cuidadosa investigación realizada por eruditos en Alemania, Francia, Suecia, Inglaterra, Israel y los Estados Unidos, y desde finales del siglo XVII, podemos informar que algunos aspectos de la vida y la enseñanza de Jesús son relativamente ciertos" (p. 98). Como se ve, se omiten todos los trabajos de España (por caso Rafael Aguirre y su grupo, Antonio Piniero) e Italia (Giuseppe Barbaglio había muerto en 2007, pero Rinaldo Fabris. Romano Penna, Adriana Destro y Mauro Pesce merecerían ser incluidos), ni tampoco del Tercer Mundo, además que llama la atención algunas ausencias, como es el caso de Joaquim Gnilka (2018) y Gerhard Lohfink, de Alemania. Ya lo dice E. Schussler (2010):

La investigación de Jesús por lo general no menciona los trabajos sobre el Jesús de la historia que han surgido en todo el mundo en forma paralela a la tercera búsqueda, pero se inspiraron en diferentes intereses y metodologías. Entre otros, Grant LeMarquand ha señalado la ignorancia de la academia occidental sobre la investigación de la minoría -histórica de África, Asia, Oceanía, Indígena, América Latina y América del Norte. Aunque los eruditos bíblicos africanos, asiáticos, latinoamericanos y poscoloniales son muy conscientes de los problemas planteados por la erudición occidental-histórica de Jesús, enmarcan y dan forma a sus propios discursos sobre Jesús de manera diferente. Su principal preocupación no es la investigación histórica de Jesús, sino deconstruir las interpretaciones colonialistas de Jesús y establecer el terreno común entre sus propias culturas y el Jesús de la historia. Se centran en el Jesús de la historia, no solo porque su cultura viene en muchos aspectos muy parecida a la suya, sino también porque sus propias culturas fueron construidas como inferiores e incluso "satánicas" por los misioneros occidentales en el nombre de Jesús. Así, la historiografía científica occidental de la investigación del Jesús histórico se constituye en y mediante la exclusión de los discursos de los "otros" y se caracteriza por el euroamericano-centrismo. La autocomprensión "científica" de la investigación del Jesús histórico justifica tales exclusiones de los discursos de los "otros". Uno se pregunta si es un accidente histórico que la tercera búsqueda del Jesús histórico explotó no solo durante el resurgimiento de Jesús, la derecha política y el resurgimiento del fundamentalismo religioso, sino también en un momento en que los movimientos de liberación de las personas y el Tercer Mundo ganaron terreno y desarrollaron un poder retórico en las iglesias y la academia (p. 526-527) ${ }^{16}$.

Ya propone González (2010) que al Conclave no papal que da origen al trabajo de John P. Meier le falta un estudioso "del Tercer Mundo". Algunos elementos que traspasan las fronteras de esa "academia occidental" implican que el Jesús histórico es tenido en cuenta en la Teología

\footnotetext{
${ }^{16}$ Como es frecuente en ella, E. Schussler al hablar de los movimientos de liberación afirma “movimientos de liberación de wo/men y el Tercer Mundo".
} 
de la Liberación desde sus orígenes (Gutiérrez, Assmann y Boff) como lo señala claramente J. Sobrino $\left(1993^{17}\right.$.

Así, por ejemplo, lo señala Ignacio Ellacuría: "la vida histórica de Jesús es la revelación más plena del Dios cristiano" (1973, p. 13, citado por Sobrino, 1993, p. 72). Algunos autores, se ha de señalar, están entusiasmados con la obra de J. D. Crossan: como es el caso de T. Cabestrero (s. f., p. 178) y J. Pixley (1998) algo que, se ha señalado, es bastante cuestionable académicamente luego de una mesurada metodología e investigación ${ }^{18}$.

En un trabajo anterior (Boff, 1990), hemos intentado hacer una distinción que nos parece oportuna. Basados en los trabajos de Boff sobre los métodos de la teología de la liberación hemos propuesto que debiera haber diferentes accesos a los estudios bíblicos (popular, pastoral y académico). En este sentido, merece citarse de Carlos Mesters, "Jesús a contramano", y se siente una mayor investigación académica sobre el tema.

Es interesante señalar que un teólogo europeo como José Ignacio González Faus afirma que:

En Europa, el Jesús histórico es objeto de investigación, mientras que en América Latina es criterio de seguimiento. En Europa, el estudio del Jesús histórico pretende establecer las posibilidades y razonabilidad del hecho de creer o no creer. En América Latina, la apelación al Jesús histórico pretende llevar ante el dilema de convertirse o no (AA.VV., 1983, p. 79).
En coherencia con esto, llama la atención la coincidencia entre dos autores muy diferentes:

- "Un Jesús cuyas palabras y hechos no encontraran rechazo, sobre todo entre los poderosos, no es el Jesús histórico" (Meier, 1991, p. 177).

- "El Cristo que no puede ser secuestrado por la gente de alto nivel económico es el Jesús histórico" (Johnson, 2004, p. 204).

De otro lado, el Jesús histórico es de importancia central en la teología feminista. Además de lo señalado por E. Schussler en el artículo citado del Handbook, es de señalar la importancia que varias teólogas conceden al Jesús histórico:

La "plena humanidad" como "marco de referencia interpretativo" dirá la misma E. Schussler (2000). Radford Reuther, dice Schussler (2000) que "concluye este capítulo con su propia respuesta constructiva, que depende fuertemente de una comprensión del Jesús histórico como profeta, liberador y representante de la humanidad liberada” (p. 75).

Johnson (2004), “(a)l buscar en la tradición elementos de una cristología que libere a las mujeres, las teólogas feministas encuentran oro en el ministerio, la muerte y la resurrección de Jesús y en la tradición de la cristología sapiencial" (p. 125). Y Vélez (2018) también afirma que:

(e)l punto de partida (...) es que una investigación sobre Jesús y las mujeres no puede limitarse a buscar los textos en que haya esa presencia de mujeres o a concentrarse en las relaciones de género. Hay que comenzar por situarse en el marco del cristianismo primitivo que dio

\footnotetext{
${ }^{17}$ Es interesante contrastar esta obra, ya elaborada, con su Cristología desde América Latina (esbozo) (1977), donde en el prólogo a la segunda edición el propio Sobrino afirma: "Los textos escriturísticos aducidos necesitan de una mayor fundamentación exegética, tratándose de una cristología que pretende basarse en el Jesús histórico (...) el análisis exegético necesita una mayor elaboración” (p. xix).

${ }^{18}$ Cfr. Pixley (2004, núm. 47).
} 
horizontes nuevos a los marginados de aquel momento, donde hay varones y mujeres que son víctimas del sistema kyriarcal (p. 68).

En África, sin duda se ha de tener en cuenta el clásico ¿Quién es este hombre? Jesús antes del cristianismo de Albert Nolan (1981), libro dedicado "A los pueblos del Tercer Mundo".

Jesús no judío: En su reciente ponencia "Christology and Mission in the Middle East" en Mainz en la conferencia internacional "Towards an Ecumenical Missiology: Witnessing Christ" (16-19 de julio 2019) Wilbert van Saane, de la Haigazian University / Near East School of Theology, destacó algunas lecturas sobre Jesús en "Medio Oriente": Karim El Koussa (2013) presenta a Jesús en su libro Jesus the Phoenician (2013). Antoine Khoury Harb en The Roots of Christianity in Lebanon (2008) ubica a Jesús en la cultura cananea. Kamal Salibi (1998) propone a Jesús como anunciador del mensaje del profeta Issa (400 a.C.) pero que fue reformulado luego de su muerte por Pedro y Santiago. El teólogo luterano Mitri Raheb (2014) publicó su libro Faith in the Face of Empire, en el que destaca un retrato de Cristo como el de uno que perteneció a los pueblos marginados de la tierra y resistió la opresión de los imperios. "Dios se identifica con esta tierra" y Jesús se manifestó en solidaridad con el “pueblo de la tierra”. Jesús revela a Dios, "en una situación de terrible agonía y dolor, cuando fue brutalmente aplastado por el imperio y colgado como un rebelde luchador por la libertad" (2014, p. 87). Se requiere de otro artículo para analizar las lecturas de teología poscolonial (en especial de África y la India).

\section{Conclusión}

Este trabajo mostró cómo se ha llegado por distintos caminos a la búsqueda del Jesús histórico (I.) y presentó los desafíos contemporáneos, tanto en el "Primer mundo", como fuera del él. Búsqueda que se revela incómoda en ocasiones, ardua, confusa, pero no por ello menos desafiante. Que se pretenda acceder, incluso desde perspectivas no creyentes al conocimiento histórico de un personaje, Jesús en este caso, no deja indiferente la fé de los que, creyentes, entendemos que la Encarnación es el punto de partida de nuestro encuentro con Dios, que la Palabra que Dios quiso decir en la historia, palabra que puso su carpa entre nosotros (Jn 1,14) es palabra que nos pone en camino de seguimiento. Conocer, aunque sea borrosamente, a Jesús evita la siempre peligrosa posibilidad de "domesticarlo". Si este trabajo provocó dudas, interrogantes y desafíos, habrá logrado su objetivo.

\section{Referencias bibliográficas}

AA.VV. (1983). Hacer' teología y hacerse teología. En Vida y reflexión. Aportes de la teología de la liberación al pensamiento teológico actual. CEP.

Ådna, J. (2010). Jesus and the Temple. En T. Holmén y S. E. Porter (eds.), Handbook for the Study of the Historical Jesus (vol. III / 3, pp. 2635-2675). Brill.

Aguirre, R. (2015). La memoria de Jesús y los cristianismos de los orígenes. Verbo Divino.

Asis, F. (1985). Jesucristo, cuyas huellas debemos seguir (XXII,1-2). BAC.

Ávila, T. (1982). Obras completas (Archivo Silveriano 1). Monte Carmelo.

Baasland, E. (2010). Fourth Quest? What Did Jesus Really Want? En Holmén, T. y Porter, S. E. (eds.), Handbook for the Study of the Historical Jesus (vol. I / 3, pp. 31-56). Brill. Back, S.O. (2010). Jesus and the Sabbath. En T. Holmén y S. E. Porter (eds.), Handbook for the Study of the Historical Jesus (vol. III / 3, pp. 2597-2633). Brill. 
Backhaus, K. (2010). Echoes from the Wilderness: The Historical John the Baptist. En Holmén, T. y Porter, S. E. (eds.), Handbook for the Study of the Historical Jesus (vol. II / 3, pp. 1747-1785). Brill.

Becker, E. M. (2010a). Historiographical Literature in the New Testament Period (1st and 2nd centuries CE). En T. Holmén y S. E. Porter (eds.), Handbook for the Study of the Historical Jesus (vol. II / 3, pp. 17871817). Brill.

Becker, J. (2010b). The Search for Jesus' Special Profile. En T. Holmén y S. E. Porter (eds.), Handbook for the Study of the Historical Jesus (vol. I / 1, pp. 57-89). Brill.

Bermejo-Rubio, F. (2019). Theses on the Nature of the Leben-Jesu-Forschung. A Proposal for a Paradigm Shift in Understanding the Quest. JSHJ, (17), 1-34.

Bird, M. F. (2010). Jesus and the 'Partings of the Ways'. En T. Holmén y S. E. Porter (eds.), Handbook for the Study of the Historical Jesus (vol. II / 2, pp. 1183-1215). Brill.

Bock, D. (2010). Jesus, Satan, and Company. En T. Holmén y S. E. Porter (eds.), Handbook for the Study of the Historical Jesus (vol. III / 3, pp. 2855-2875). Brill.

Bockmuehl, M. (ed.) (2001). The Cambridge companion to Jesus. Cambridge.

Boff, C. (1990). Epistemología y método de la teología de la liberación. En J. Sobrino y I. Ellacuría, Mysterium Liberationis (vol. I, pp. 79-113, 93). Trotta.

Broadhead, E. K. (2010a). Implicit Christology and the Historical Jesus. En T. Holmén y S. E. Porter (eds.), Handbook for the Study of the Historical Jesus (vol. II / 2, pp. 11691182). Brill.

Broadhead, E. K. (2010b). The Thomas-Jesus Connection. En T. Holmén y S. E. Porter (eds.), Handbook for the Study of the
Historical Jesus (vol. III / 1, pp. 2059-2080). Brill.

Brown, C. (2010). The Quest of the Unhistorical Jesus and the Quest of the Historical Jesus. En T. Holmén y S. E. Porter (eds.), Handbook for the Study of the Historical Jesus (vol. II / 1, pp. 855-886). Brill.

Brown, C. (2010). Why Study the Historical Jesus?. En T. Holmén y S. E. Porter (eds.), Handbook for the Study of the Historical Jesus (vol. II / 2, pp. 1411-1438). Brill.

Brown, C. (2010). With the Grain and against the Grain: A Strategy for Reading the Synoptic Gospels. En T. Holmén y S. E. Porter (eds.), Handbook for the Study of the Historical Jesus (vol. I / 2, pp. 619-648). Brill.

Bryan, S. M. (2010). Jesus and Israel's Eschatological Constitution. En T. Holmén y S. E. Porter (eds.), Handbook for the Study of the Historical Jesus (vol. III / 3, pp. 28352853). Brill.

Byrskog, S. (2010). The Historicity of Jesus: How Do We Know That Jesus Existed?. En T. Holmén y S. E. Porter (eds.), Handbook for the Study of the Historical Jesus (vol. III / 2, pp. 2183-2211). Brill.

Byrskog, S. (2010). The Transmission of the Jesus Tradition. En T. Holmén y S. E. Porter (eds.), Handbook for the Study of the Historical Jesus (vol. II / 3, pp. 1465-1494). Brill.

Casey, M. (2010). The Role of Aramaic in Reconstructing the Teaching of Jesus. En T. Holmén y S. E. Porter (eds.), Handbook for the Study of the Historical Jesus (vol. II / 2, pp. 1343-1375). Brill.

Charlesworth, J. H. (2020). The Historical Jesus: How to Ask Questions and Remain Inquisitive. p. 116. En T. Holmén y S. E. Porter (eds.), Handbook for the Study of the Historical Jesus (vol. I / 1, pp. 91-128). Brill. 
Charlesworth, J. H. (2010). The Historical Jesus: How to Ask Questions and Remain Inquisitive. En T. Holmén y S. E. Porter (eds.), Handbook for the Study of the Historical Jesus (vol. I / 1, pp. 91-128). Brill.

Chilton, B. D. (2010a). Method in a Critical Study of Jesus. En T. Holmén y S. E. Porter (eds.), Handbook for the Study of the Historical Jesus (vol. I / 1, pp. 129-158). Brill.

Chilton, B. (2010b). Jesus and Sinners and Outcasts. En T. Holmén y S. E. Porter (eds.), Handbook for the Study of the Historical Jesus (vol. III / 3, pp. 2801-2833). Brill.

Collins, J. J. (2010). The Son of Man in Ancient Judaism. En T. Holmén y S. E. Porter (eds.), Handbook for the Study of the Historical Jesus (vol. II / 3, pp. 1545-1568). Brill.

Crossan, J. D. (2010). Context and Text in Historical Jesus Methodology. En T. Holmén y S. E. Porter (eds.), Handbook for the Study of the Historical Jesus (vol. I / 1, pp. 159181). Brill.

De la Serna, E. (2019). Pablo seguidor del Jesús de la historia. RevBib, 81(14), 183-196.

Dewey, J. (2010). The Historical Jesus in the Gospel of Mark. En T. Holmén y S. E. Porter (eds.), Handbook for the Study of the Historical Jesus (vol. III / 1, pp. 18211852). Brill.

Downing, F. G. (2010). Jesus and Cynicism. En T. Holmén y S. E. Porter (eds.), Handbook for the Study of the Historical Jesus (vol. II / 2, pp. 1105-1136). Brill.

Dungan, D. L. (2010). Dispensing with the Priority of Mark (II / 2, pp. 1313-1342). En T. Holmén y S. E. Porter (eds.), Handbook for the Study of the Historical Jesus (vol. II / 2, pp. 1313-1342). Brill.

Dunn, J. D. G. (2010). Remembering Jesus: How the Quest of the Historical Jesus Lost its Way. En T. Holmén y S. E. Porter (eds.),
Handbook for the Study of the Historical Jesus (vol. I / 1, pp. 183-205). Brill.

El Koussa, K. (2013). Jesus the Phoenician. Sunbury Press.

Evans, C. A. (2010). Prophet, Sage, Healer, Messiah, and Martyr: Types and Identities of Jesus. En T. Holmén y S. E. Porter (eds.), Handbook for the Study of the Historical Jesus (vol. II / 2, pp. 1217-1243). Brill.

Farrer, A. (1955). On Dispensing With Q, 1955.

Fletcher-Louis, C. (2010a). Jesus and Apocalypticism. En T. Holmén y S. E. Porter (eds.), Handbook for the Study of the Historical Jesus (vol. III / 3, pp. 2877-2909). Brill.

Fletcher-Louis, C. (2010b). Jewish Apocalyptic and Apocalypticism. En T. Holmén y S. E. Porter (eds.), Handbook for the Study of the Historical Jesus (vol. II / 3, pp. 15691607). Brill.

France, R. T. (2010). The Birth of Jesus (III / 2, pp. 2361-2382). En T. Holmén y S. E. Porter (eds.), Handbook for the Study of the Historical Jesus (vol. III / 2, pp. 2361-2382). Brill.

Funk, R. W. y Jesus Seminar (1993). The Five Gospels: What Did Jesus Really Say? the Search for the Authentic Words of Jesus. Harper

Goodacre, M. (2007). Abandoning "the third quest" of the Historical Jesus. Recuperado de http://ntweblog.blogspot.com/2007/04/ abandoning-third-quest-of-historical.html

Goulder, M. (2010). Jesus without Q. En T. Holmén y S. E. Porter (eds.), Handbook for the Study of the Historical Jesus (vol. II / 2, pp. 1287-1311). Brill.

Grabbe, L. L. (2010). Synagogue and Sanhedrin in the First Century. En T. Holmén y S. E. Porter (eds.), Handbook for the Study of the Historical Jesus (vol. II / 3, pp. 17231745). Brill. 
Green, J. B. (2010). Family, Friends, and Foes. En T. Holmén y S. E. Porter (eds.), Handbook for the Study of the Historical Jesus (vol. III / 2, pp. 2433-2453). Brill.

Hagner, D. A. (2010). The Jesus Quest and JewishChristian Relations (II / 1, pp. 1055-1077). En T. Holmén y S. E. Porter (eds.), Handbook for the Study of the Historical Jesus (vol. II / 1, pp. 1055-1077). Brill.

Hoehner, H. W. (2010). The Chronology of Jesus (III / 2, pp. 2315-2359). En T. Holmén y S. E. Porter (eds.), Handbook for the Study of the Historical Jesus (vol. III / 2, pp. 23152359). Brill.

Holmberg, B. (2010). Futures for the Jesus Quests (II / 1, pp. 887-917). En T. Holmén y S. E. Porter (eds.), Handbook for the Study of the Historical Jesus (vol. II / 1, pp. 887917). Brill.

Holmén, T. y Porter, S. E. (eds.) (2010). Handbook for the Study of the Historical Jesus (4 vols.). Brill.

Horsley, R. A. (2010). Jesus-in-Context: A Relational Approach (I / 1, pp. 207-239). En T. Holmén y S. E. Porter (eds.), Handbook for the Study of the Historical Jesus (vol. I / 1, pp. 207-239). Brill.

Huat Tan, K. (2010). Jesus and the Shema. En T. Holmén y S. E. Porter (eds.), Handbook for the Study of the Historical Jesus (vol. III / 3, pp. 2677-2707). Brill.

Hultgren, A. J. (2010). Form Criticism and Jesus Research. En T. Holmén y S. E. Porter (eds.), Handbook for the Study of the Historical Jesus (vol. I / 2, pp. 649-671). Brill.

Instone-Brewer, D. (2010). Rabbinic Writings in New Testament Research. En T. Holmén y S. E. Porter (eds.), Handbook for the Study of the Historical Jesus (vol. II / 3, pp. 16871721). Brill.

Johnson, E. (2004). La palabra se hizo carne y habitó entre nosotros. En D. Donnelly (ed.), Un coloquio en Tierra Santa. Verbo Divino.

Johnson, L. T. (2010). Anti-Judaism and the New Testament. En T. Holmén y S. E. Porter (eds.), Handbook for the Study of the Historical Jesus (vol. II / 3, pp. 16091638). Brill.

Kähler (1892). Der sogenannte historische Jesus und der geschichtliche, biblische Christus. Böhme.

Käsemann, E. (1978). El problema del Jesús histórico. Ensayos exegéticos. Sígueme.

Khoury Harb, A. (2008). The Roots of Christianity in Lebanon (N. Nasr trad.). Lebanese Heritage Foundation.

Kirk, A. (2010). Memory Theory and Jesus Research. En T. Holmén y S. E. Porter (eds.), Handbook for the Study of the Historical Jesus (vol. I / 2, pp. 809-842). Brill.

Kloppenborg, J. S. (2005). El evangelio desconocido. Sígueme

Kloppenborg, J. S. (2010). Sources, Methods and Discursive Locations in the Quest of the Historical Jesus (I / 1, pp. 241-290). En T. Holmén y S. E. Porter (eds.), Handbook for the Study of the Historical Jesus (vol. I / 1, pp. 241-290). Brill.

Kreplin, M. (2010). The Self-Understanding of Jesus. En T. Holmén y S. E. Porter (eds.), Handbook for the Study of the Historical Jesus (vol. III / 2, pp. 2473-2516). Brill.

Kuhn, H.W. (2010). Jesus im Licht der Qumrangemeinde. En T. Holmén y S. E. Porter (eds.), Handbook for the Study of the Historical Jesus (vol. II / 2, pp. 12451285). Brill.

Labahn, M. (2010). The Non-Synoptic Jesus: An Introduction to John, Paul, Thomas, 
and Other Outsiders of the Jesus Quest. En T. Holmén y S. E. Porter (eds.), Handbook for the Study of the Historical Jesus (vol. III / 1, pp. 1933-1996). Brill.

Levine, A. J. (2014). Relatos cortos de Jesús. Las parábolas enigmáticas de un rabino polémico. Verbo Divino.

Loader, W. (2010). Jesus and the Law. En T. Holmén y S. E. Porter (eds.), Handbook for the Study of the Historical Jesus (vol. III / 3, pp. 2745-2772). Brill.

Malina, B. J. (2010). Social-Scientific Approaches and Jesus Research. En T. Holmén y S. E. Porter (eds.), Handbook for the Study of the Historical Jesus (vol. I / 2, pp. 743-775). Brill.

Marsh, C. (2010). Diverse Agendas at Work in the Jesus Quest. En T. Holmén y S. E. Porter (eds.), Handbook for the Study of the Historical Jesus (vol. II / 1, pp. 985-1020). Brill.

Mason, S. (2010). The Writings of Josephus: Their Significance for New Testament Study (II / 3, pp. 1639-1686). En T. Holmén y S. E. Porter (eds.), Handbook for the Study of the Historical Jesus (vol. II / 3, pp. 16391686). Brill.

Mayordomo, M. y Smit, P. B. (2010). The Quest for the Historical Jesus in Postmodern Perspective: A Hypothetical Argument. En T. Holmén y S. E. Porter (eds.), Handbook for the Study of the Historical Jesus (vol. II / 2, pp. 1377-1409). Brill.

McKnight, S. (2010). The Parable of the Goose and the Mirror: The Historical Jesus in the Theological Discipline. En T. Holmén y S. E. Porter (eds.), Handbook for the Study of the Historical Jesus (vol. II / 1, pp. 919951). Brill.

McNamara, M. (2010). Background II: (Some)
Literary Documents. En T. Holmén y S. E. Porter (eds.), Handbook for the Study of the Historical Jesus (vol. III / 2, pp. 22432290). Brill.

Meier, J. P. (1991). A Marginal Jew. Rethinking the Historical Jesus I. Doubleday.

Meier, J. P. (2010). Otro mundo es posible... desde Jesús. Sal Terrae.

Meier, J. P. (2016). A Marginal Jew. Yale University Press.

Moyise, S. (2010). Jesus and the Scriptures of Israel. En T. Holmén y S. E. Porter (eds.), Handbook for the Study of the Historical Jesus (vol. II / 2, pp. 1137-1167). Brill.

Neil, S. y Wright, T. (1988). The Interpretation of the New Testament 1861-1986. Rev. ed. Oxford, 379-403.

Nicklas, T. (2010a). Traditions about Jesus in Apocryphal Gospels (with the Exception of the Gospel of Thomas). En T. Holmén y S. E. Porter (eds.), Handbook for the Study of the Historical Jesus (vol. III / 1, pp. 20812118). Brill.

Nicklas, T. (2010b). Alternatives to Form and Tradition Criticism in Jesus Research. En T. Holmén y S. E. Porter (eds.), Handbook for the Study of the Historical Jesus (vol. I / 2, pp. 715-742). Brill.

Nodet, E. (2010). Pharisees, Sadducees, Essenes, Herodians. En T. Holmén y S. E. Porter (eds.), Handbook for the Study of the Historical Jesus (vol. II / 3, pp. 1495-1543). Brill.

Nolan, A. [1981(1976)]. ¿Quién es este hombre? Jesús antes del cristianismo. Sal Terrae.

Nolland, J. (2010). Luke and Acts. En T. Holmén y S. E. Porter (eds.), Handbook for the Study of the Historical Jesus (vol. III / 1, pp. 1901-1931). Brill.

Okure, T. (2010). Historical Jesus Research in Global Cultural Context. En T. Holmén y 
S. E. Porter (eds.), Handbook for the Study of the Historical Jesus (vol. II / 1, pp. 953984). Brill.

Osborne, G. R. (2010). Tradition Criticism and Jesus Research. En T. Holmén y S. E. Porter (eds.), Handbook for the Study of the Historical Jesus (vol. I / 2, pp. 673-693). Brill.

Perkins, P. (2010). The Resurrection of Jesus. En T. Holmén y S. E. Porter (eds.), Handbook for the Study of the Historical Jesus (vol. III / 2, pp. 2409-2432). Brill.

Pixley, J. (1998). Recensión a Um judeu marginal. Repensando o Jesús histórico. RIBLA, (30), 175-178.

Pixley, J. (2004). Jesús histórico. RIBLA, 1(47).

Pixner, B. (1992). With Jesus Through Galilee According to the Fifth Gospel. Rosh Pina.

Pokorný, P. (2010). Jesus Research as Feedback on His Wirkungsgeschichte. En T. Holmén y S. E. Porter (eds.), Handbook for the Study of the Historical Jesus (vol. I / 1, pp. 333359). Brill.

Porter, S. E. (2010). The Context of Jesus: Jewish and/or Hellenistic?. En T. Holmén y S. E. Porter (eds.), Handbook for the Study of the Historical Jesus (vol. II / 3, pp. 14411463). Brill.

Raheb, M. (2014). Faith in the Face of Empire: The Bible through Palestinian Eyes. Orbis Books.

Riesner, R. (2010). From the Messianic Teacher to the Gospels of Jesus Christ. En T. Holmén y S. E. Porter (eds.), Handbook for the Study of the Historical Jesus (vol. I / 1, pp. 405-446). Brill.

Robinson, J. M. (2010). The Gospel of the Historical Jesus. En T. Holmén y S. E. Porter (eds.), Handbook for the Study of the Historical Jesus (vol. I / 1, pp. 447-474). Brill.

Salibi, K. (1998). Who Was Jesus? A Conspiracy in Jerusalem. I.B. Tauris \& Co Ltd.
Schlosser, J. (2010a). Scholarly Rigor and Intuition in Historical Research into Jesus. En Holmén, T. y Porter, S. E. (eds.), Handbook for the Study of the Historical Jesus (vol. I / 1, pp. 475-507). Brill.

Schussler, E. [2000 (1994)]. Cristología feminista crítica. Jesús, Hijo de Miriam, Profeta de la Sabiduría. Trotta.

Sobrino, J. (1993). Jesucristo liberador. Lectura histórico-teológica de Jesús de Nazareth (pp. 71-72 y 76-79). Trotta

Stegemann, W. (2010). Background III: The Social and Political Climate in which Jesus of Nazareth Preached. En T. Holmén y S. E. Porter (eds.), Handbook for the Study of the Historical Jesus (vol. III / 2, pp. 22912314). Brill.

Theissen, G. (2010). Historical Scepticism and the Criteria of Jesus Research: My Attempt to Leap Over Lessing's Ugly Wide Ditch (I / 1, pp. 549-587). En T. Holmén y S. E. Porter (eds.), Handbook for the Study of the Historical Jesus (vol. I / 1, pp. 549-587). Brill.

Trevijano, R. (1997). Estudios sobre el Evangelio de Tomás (Fuentes patrísticas, Estudios 2). Ciudad Nueva.

Tuckett, C. (2010). Jesus Tradition in nonMarkan Material Common to Matthew and Luke. En T. Holmén y S. E. Porter (eds.), Handbook for the Study of the Historical Jesus (vol. III / 1, pp. 1853-1874). Brill.

Twelftree, G. H. (2010). The Message of Jesus I: Miracles, Continuing Controversies. En T. Holmén y S. E. Porter (eds.), Handbook for the Study of the Historical Jesus (vol. III / 2, pp. 2517-2548). Brill.

Van Voorst, R. E. (2010). Jesus Tradition in Classical and Jewish Writings. En T. Holmén y S. E. Porter (eds.), Handbook for the Study of the Historical Jesus (vol. III / 1, pp. 
2149-2180). Brill.

Vélez, C. (2018). Cristología y mujer. Una reflexión necesaria para una fé incluyente. Editorial Pontificia Universidad Javeriana.

Vermes, G. (2012). Christian begginings, from Nazareth to Nicaea (AD 30-325). Penguin books.

Wenell, K. J. (2010). Jesus and the Holy Land. En T. Holmén y S. E. Porter (eds.), Handbook for the Study of the Historical Jesus (vol. III
/ 3, pp. 2773-2799). Brill.

Wenham, D. (2010). Jesus Tradition in the Letters of the New Testament. En T. Holmén y S. E. Porter (eds.), Handbook for the Study of the Historical Jesus (vol. III / 1, pp. 20412057). Brill.

Winter, D. (2010). The Burden of Proof in Jesus Research. En T. Holmén y S. E. Porter (eds.), Handbook for the Study of the Historical Jesus (vol. I / 2, pp. 843-851). Brill.

Wright, N. T. (1992). Jesus, Quest for the Historical. En D. N. Freedman (ed.), ABD, 6(3), 796-802.

Zumstein, J. (2019). Memoire, histoire et fiction dans la litterature johannique. NTS, 65, 136. 